Reseña a Cristina Carrasco Bengoa y Carmen Díaz Corral (Eds.) (2018),

Economía feminista. Desafíos, propuestas, alianzas

Carolina Clavero White

Con X (N. $\left.{ }^{\circ} 8\right), \mathrm{e} 042,2022$

ISSN 2469-0333 | https://doi.org/10.24215/24690333e042

http://perio.unlp.edu.ar/ojs/index.php/conequis

FPyCS | Universidad Nacional de La Plata

La Plata | Buenos Aires | Argentina

\title{
Reseña a Economía feminista. Desafíos, propuestas, alianzas
}

\section{Cristina Carrasco Bengoa y Carmen Díaz Corral (Eds.) (2018)}

Review to Feminist Economics. Challenges, Proposals, Alliances

Cristina Carrasco Bengoa y Carmen Díaz Corral (Eds.) (2018)

\section{Carolina Clavero White}

caroclave@gmail.com

https://orcid.org/0000-0001-5238-8180

Facultad Latinoamericana de Ciencias Sociales (FLACSO-Uruguay) Consejo de Formación en Educación | Uruguay

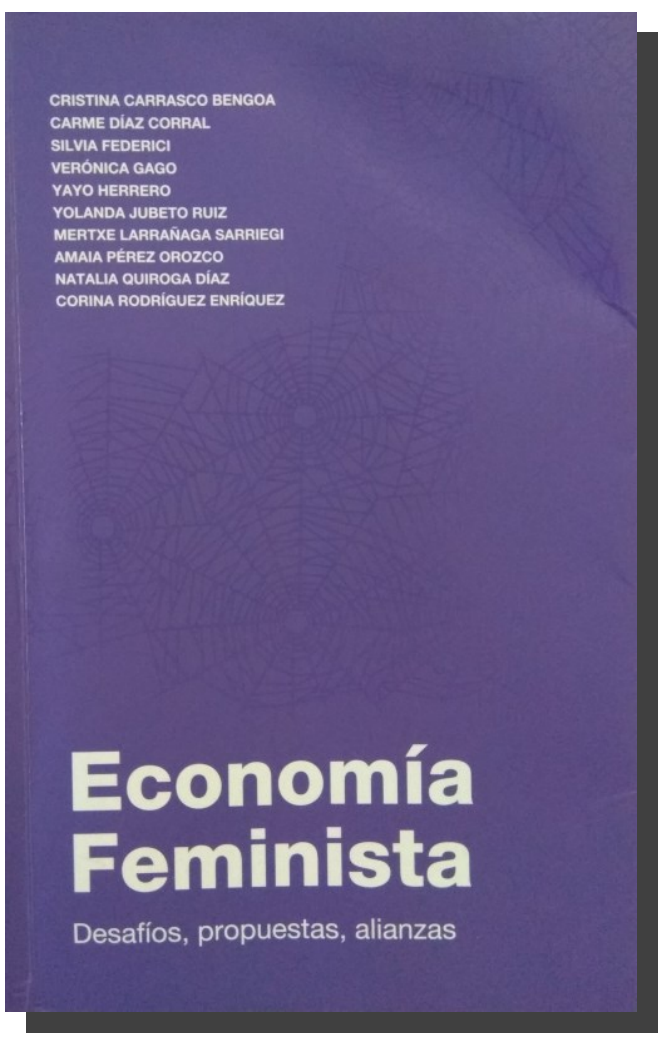

Ciudad Autónoma de Buenos Aires, Argentina Madreselva | 160 páginas | ISBN 978-987-3861-20-8 
Imaginemos a un/a bebe de pocos meses apoyado/a sobre una cama o a un/a niño/a de uno o dos años en una habitación. En cualquier caso, están en soledad... ¿Cuánto tiempo podrían soportar la existencia sin riesgos? ¿Cuánto tiempo podríamos pasar indiferentes, sin ofrecer palabras, orientación, comida, vestimenta o juego? Resulta que esa interdependencia que hace posible la existencia humana tiene un inmenso valor; tal es así, que si hoy vivimos es porque hubo tiempos, espacios y personas que hicieron posible nuestra propia vida. El asunto que le interesa resaltar a la economía feminista de ese cuadro imaginario es que la responsabilidad de sacar adelante los procesos vitales se sumerge en las esferas económicas invisibilizadas, donde queda a veces privatizada $\mathrm{y}$, generalmente, feminizada (Pérez Orozco, 2018, p. 25). También nos hace conscientes del hecho de que «en esta sociedad el concepto económico de valor es tan perverso que producir armas que matan niñxs es considerado productivo, una contribución a la riqueza social, mientras que ayudar a crecer a lxs niñxs no lo es» (Federici, 2018, pp. 16-17).

El libro que aquí se reseña corresponde a la primera edición realizada por Madreselva y, como se indica en la solapa de la obra, ues producto de una red de afectos y de complicidades feministas y anticapitalistas», nutrida del apoyo mutuo, la voluntad y la circulación libre de la palabra hecha propuesta y acción común. Le antecede una edición española de 2017. En ambos casos, la red está conformada por activistas e intelectuales de América Latina y de Europa: Entrepueblos (asociación de solidaridad internacional independiente, feminista y con base social activista, constituida en 1988 por los Comités de Solidaridad con América Latina) convocó a Cristina Carrasco Bengoa y a Carmen Díaz Corral con el propósito de explorar y de recoger los retos y los desarrollos de la economía feminista. Ambas economistas, docentes e investigadoras apoyaron la coordinación y propiciaron la colaboración desinteresada de algunas de las mejores voces de la economía feminista tales como Silvia Federici, Amaia Pérez Orozco, Mertxe Larrañaga Sarriegi, Yolanda Jubeto Ruiz, Natalia Quiroga Díaz, Verónica Gago, Yayo Herrero y Corina Rodríguez Enríquez. 
El tema central que recorre todos los artículos es el llamado «conflicto capital-vida», asunto que resulta tratado de forma sintética pero profunda, típico de personas eruditas en el objeto de estudio. En este caso, la erudición no surge solamente de la teoría, sino de las prácticas colectivas. Se asume una visión de la economía feminista propia de la Red de Economía Feminista de España, a la que pertenecen las autoras desde su creación, y se considera que la relación más cercana por historia, cultura y lengua es con América Latina. De ese vínculo se nutre la economía feminista con la idea de colonialidad, tema desarrollado con fuerza durante la última década por las economistas feministas latinoamericanas.

Entra las fortalezas del texto destaca, por una parte, la posibilidad de ampliar nuestros conocimientos mediante los instrumentos para la interpretación de la realidad desde un lenguaje comprensible para no economistas o, como sostiene Federici (2018), a partir de «desmitificar un lenguaje técnico que se filtra constantemente en el discurso político con los mismos efectos intimidatorios que tuvo el uso del latín» (p. 17). Por otra parte, se ofrecen numerosas referencias a documentos colectivos y a propuestas prácticas para los niveles macro, meso y micro, pero no a modo de recetario cerrado o de manual de instrucciones sino como «pistas por donde ir y un horizonte de transición al que acercarnos» (Pérez Orozco, 2018, p. 29).

En ese recorrido, se presenta lo que las autoras conciben como economía feminista, que no constituye una rama más de la economía sino otra manera de entender el mundo. Se trata de una propuesta rupturista con lo establecido que va fraguándose con fuerza tanto desde el campo teórico como político. Para esto, establecen dos premisas fundamentales: la interdependencia de los seres humanos para hacer posible la vida (lo que requiere del cuidado de otros/as en todos los ciclos de la vida) y la interdependencia humana con la biosfera (lo que implica asumir los límites de la naturaleza). En ese sentido, el objetivo último de la economía feminista frente al conflicto capital-vida es apostar por la vida; aventurar nuevos enfoques, subversivos respecto del sistema económico hegemónico, que lleven a procesos emancipadores e incluyentes.

Las 160 páginas inician con una Presentación [pp. 7-14], a cargo de las editoras, que permite conocer cómo surge la economía feminista, cuales son las críticas que establece a las tradiciones existentes en economía (fundamentalmente, la teoría neoclásica) y cuáles son los temas centrales que se han discutido y practicado. 
Le siguen dos capítulos relacionados con el campo aplicado, en los que se reflexiona sobre las políticas o las acciones en sintonía con la propuesta teórica. En el primero, «Economía feminista entre movimientos e instituciones: posibilidades, límites, contradicciones» [pp. 15-22], Silvia Federici apuesta a que la economía feminista se convierta en un nexo importante y necesario entre los movimientos sociales y las instituciones, considerando que son estos los que pueden generar transformaciones significativas. Pero el planteo no es idealista, sino más bien propositivo: para «hacernos comprender esta realidad y, sobre todo, ayudarnos a comprender cuál es la lógica del sistema social que enfrentamos» (2018, p. 20); para ayudarnos «a descifrar, a desenmascarar el lenguaje de la planificación económica, de manera que podamos anticipar las direcciones de los proyectos económicos del capital internacional» (2018, p. 20); para profundizar «la explicación de la importancia del trabajo de reproducción no solamente para nuestras vidas y para la acumulación capitalista, sino también para nuestra lucha: para la construcción de economías solidarias, de procesos colectivos de auto organización, capaces de incrementar nuestra autonomía del mercado y nuestra resistencia al control del Estado sobre nuestras vidas» (2018, p. 21).

El segundo capítulo «¿Espacios económicos de subversión feminista?» [pp. 23-50] está escrito con gran rigor por Amaia Pérez Orozco. Al principio, se plantean delimitaciones conceptuales sobre el enfoque: por ejemplo, a qué se llama y cómo se caracteriza el sistema económico hegemónico, «que a veces optamos por nombrar, breve e irónicamente, como esa Cosa escandalosa» (2018, p. 24); qué se entiende por vida y cómo se le da sentido desde esa hegemonía que es capitalista, hetero patriarcal, medioambientalmente destructora, colonialista y racista. En palabras de la autora, «los espacios económicos de subversión feminista son aquellos en los que vamos articulando una responsabilidad colectiva en hacer posible la vida, asumiendo los límites del planeta del que somos parte; al mismo tiempo que van dotando de contenido a una noción diferente del buen convivir» (2018, p. 27). Es un capítulo ocupado en recoger propuestas y acciones; en imaginar esos espacios subvertidos, diversos, en red, descomplejizados (esto es, acercando las acciones a sus consecuencias), relocalizados, autónomos y soberanos.

Le siguen tres capítulos que abordan la relación con otras economías críticas alternativas: «Contribuciones de la economía feminista a la construcción de una economía solidaria» [pp. 51-76], a cargo de Mertxe Larrañaga y de Yolanda Jubero; 
«Una mirada feminista de la economía urbana y los comunes en la reinvención de la ciudad» [pp. 77-109], a cargo de Natalia Quiroga y de Verónica Gago; y «Economía ecológica y economía feminista: un diálogo necesario» [pp. 111-131], con reflexiones de Yayo Herrero.

El libro finaliza con el artículo de Corina Rodríguez, «Economía del cuidado y desigualdad en América Latina: avances recientes y desafíos pendientes» [pp. 133156], donde se atiende, de manera más específica, la realidad de América Latina en torno a los cuidados o al derecho de ser cuidado y a la organización social, respecto de lo cual destaca como referencia relevante la experiencia de Uruguay.

Sin duda, es un libro ineludible para la reflexión colectiva, porque la comprensión de las estructuras económicas desde la mirada feminista significa acercarnos a los núcleos duros en los que se articula el poder que domina nuestra sociedad. Como sostienen las autoras de esta obra, es necesario comprender la economía para subvertirla, «y también para asegurar que nuestra reproducción, nuestra felicidad, no la logremos a costa de la explotación y del sufrimiento de ninguna persona en ninguna parte del planeta» (Federici, 2018, p. 22).

Desde el punto de vista disciplinar, la economía feminista aquí presentada es una muestra más de los cambios paradigmáticos que han protagonizado los feminismos en los marcos interpretativos de la realidad. La reflexión sustentada en la intersección de género, clase, raza y territorio permite comprender los supuestos androcéntricos de los conceptos y las metodologías dominantes de la economía. Asimismo, no solo se destacan las experiencias colectivas de las mujeres mediante la revalorización de sus prácticas y sus contribuciones al desarrollo social sino que está implícita una invitación a participar de la subversión de las relaciones de saber-poder. Perder el miedo a aquellas disciplinas que resultaron nichos masculinos; colocar en el centro de los debates, de los análisis críticos y de la práctica política los saberes proporcionados por la economía, sin dejar de vigilar que lo que hace posible la vida permanezca en el centro de todos nuestros proyectos alternativos. 